\title{
As representações sociais de conjugalidade entre casais recasados
}

\author{
Priscilla de Oliveira Martins Silva \\ Zeidi Araujo Trindade \\ Annor da Silva Junior \\ Universidade Federal do Espírito Santo
}

\begin{abstract}
Resumo
O presente trabalho tem como objetivo analisar as representações sociais (RS) de conjugalidade em casais recasados. Foram realizados 2 grupos focais ( $1 \mathrm{com}$ mulheres e 1 com homens). Os participantes possuem ao menos um filho no primeiro casamento e residem em bairros considerados de classe média ou média alta. Para a análise dos dados foi utilizada a análise de discurso. Os resultados revelam que a RS da conjugalidade configura-se como um sistema representacional, já que os elementos que a compõem são considerados objetos sociais, e; que se organiza de maneira diferente para homens e mulheres. Também, observou-se no recasamento: 1) alto grau de complexidade nas relações familiares; 2) os filhos, na visão dos pais, lidam bem com a nova dinâmica familiar; 3) a relação conjugal tende a ser mais igualitária; 4) os homens parecem apresentar a necessidade de uma parceria conjugal para a organização da vida emocional, familiar e profissional.
\end{abstract}

Palavras-chave: conjugalidade; recasamento; representações sociais.

\begin{abstract}
Social representations of conjugality among remarried couples. The present study aims to analyze social representations (SR) of conjugality among remarried couples. Two focus groups were held, one group with women and one group with men. All participants have at least one child from their first marriage and live at a considered middle or high-middle class neighborhood. The data were analyzed by discourse analyze. The results show conjugality SR is organized as a representational system, because the elements, that are articulated in order to form it, are considered social objects. The SR observed is organized differently by men and women. Also, it was observed in remarriage: 1) high complexity degree among family relations; 2) children, on parents point of view, deal with the new family dynamic nicely; 3) tendency of more equal conjugal relations; 4) men seem to need a conjugal partnership to organize their emotional, family and professional life.
\end{abstract}

Keywords: conjugality; remarriage; social representations.

$\mathrm{O}$ $\mathrm{s}$ estudos sobre a conjugalidade abrangem grande diversidade de assuntos como o amor, as relações e os conflitos conjugais, a influência da relação conjugal na criação dos filhos, o processo de separação, satisfação conjugal, satisfação sexual, entre outros (Dessen \& Braz, 2005; Féres-Carneiro \& Neto, 2010). Observa-se interesse crescente da academia no relacionamento conjugal, que se expressa no número também crescente de estudos sobre o tema (FéresCarneiro \& Neto, 2010). Isso tem ocorrido, provavelmente, devido às mudanças nos valores e comportamentos relacionados ao casamento (Cano, Gabarra, Moré, \& Crepaldi, 2009), tais como aumento da idade média dos noivos e aumento da expectativa de vida (IBGE, 2010); diminuição da importância da família biológica na escolha do cônjuge e maior envolvimento do indivíduo na escolha do parceiro (Araújo, 2002; Bawin-Legros, 2001; Bulcroft, Bulcroft, Bradley, \& Simpson, 2000; Giddens, 1993), e transformações nas relações de gênero, expressas por meio de maior controle da natalidade, da inserção intensa da mulher no mercado de trabalho, das modificações ocorridas no campo da sexualidade, dentre outros aspectos (Peixoto, 2007).

De acordo com Bawin-Legros (2004) a família continua a ser um valor importante e o casamento continua sendo o lugar onde a intimidade é construída e experienciada. Observa-se, todavia, que recentemente a noção de casamento foi ampliada, pois já não é tão fácil definir um casal. Um casal pode ter várias formas: estar casado formalmente, apenas conviver no mesmo local, ou ainda cada membro do casal viver separadamente (Bawin-Legos, 2004). Já Gomes e Paiva (2003) chamam 
a atenção para a mudança no sentido de família com os recasamentos, com a família podendo também se constituir de padrasto, mãe, filhos e enteados, como de madrasta, pai, filhos e enteados. A complexidade da família e as dificuldades aumentam se houver mais de um recasamento, como argumentam Bucher e Rodrigues (1990) e Dias (2006). Segundo esses autores, as dificuldades estão associadas às diferentes relações biológicas e emocionais da família anterior e da(s) nova(s) família(s) reconstituída(s). Para Souza e Ramirez (2006) as dificuldades estão relacionadas à redefinição do conteúdo dos papéis, funções, responsabilidades e poder.

Diante da nova realidade sobre as relações familiares, esta pesquisa teve o objetivo de investigar como as pessoas que se encontram em um recasamento representam socialmente a conjugalidade. É importante ressaltar que o presente estudo adota uma perspectiva distinta da maioria dos estudos sobre conjugalidade no Brasil. Observa-se que a temática da conjugalidade costuma ser abordada em Psicologia pela perspectiva clínica, neste artigo assume a perspectiva psicossociológica para a compreensão do fenômeno em questão.

\section{$O$ recasamento}

Os estudos sobre o recasamento começaram a surgir no cenário científico na década de 1970, e diversos autores indicam que as primeiras pesquisas ocorreram nos Estados Unidos (Bucher \& Rodrigues, 1990; Guerreiro, Oliveira, \& Souza, 1999). No Brasil, os trabalhos sobre esta temática tiveram início na década de 1980 (Bucher \& Rodrigues, 1990), contudo em número bastante reduzido. Ainda hoje observa-se a escassez de pesquisas brasileiras sobre o tema recasamento (Cano et al., 2009), apesar do já apontado interesse crescente nos aspectos relacionados à conjugalidade.

Os primeiros estudos sobre o recasamento surgiram na década de 1970 e abordavam mais especificamente dados demográficos ou realizavam levantamento de literatura sobre o assunto. A partir da década de 1980, outros interesses foram surgindo, tais como: (1) opinião, percepção, visão, crenças, valores dos envolvidos (pais, padrastos, madrastas e crianças); (2) modelos de intervenção; (3) funcionamento da família recasada; (4) consequências do recasamento no desenvolvimento dos filhos; (5) recasamento e saúde; (6) questões legais e casos específicos de famílias recasadas (famílias homossexuais e famílias de imigrantes) (Guerreiro et al., 1999).

É importante ressaltar que no passado existiam famílias reconstituídas, formadas por padrastos, madrastas e meiosirmãos. A mudança nessa estrutura surge efetivamente quando os pais biológicos estão vivos e levam uma vida separada ou inserida em outra família (Kunrath, 2006).

Com a visibilidade dessa nova estrutura familiar, uma das questões discutidas entre os pesquisadores foi a sua denominação. Os termos surgidos para nomear as famílias que se mantiveram casadas foram família de primeiro casamento, família intacta e original ou nuclear. Para as famílias que se encontram em segundo casamento, os termos foram recasamento, família recasada, família resconstituída ou recomposta ou recombinada (Bucher \& Rodrigues, 1990). Alguns dos termos surgidos, de acordo com Bucher e Rodrigues (1990), revelam a valorização da família do primeiro casamento. Os termos família intacta ou original e família reconstituída ou recomposta apresentam a família originada do primeiro casamento como o modelo a ser seguido. Diante dessa realidade, esses autores acreditam ser melhor denominar a família de primeiro casamento dessa forma mesmo - família de primeiro casamento -, uma vez que é apenas um termo descritivo, e a família composta pelo segundo casamento de família recasada. Isso porque a ênfase recai no casamento (os cônjuges é que são recasados), e não na tentativa de reconstruir uma família original. Diferentemente, para Cano et al. (2009) a palavra recasamento também não é a mais adequada, isso porque o uso do prefixo "re" passa a ideia de repetição, de reformulação e de recriação, recaindo novamente a ênfase na família nuclear original. Os autores, porém, não propõem uma alternativa diferente, por isso será utilizada no presente artigo a palavra recasamento.

O conceito de família recasada será tratado aqui como uma família formada "por dois adultos que se unem formando uma nova família para a qual um ou ambos trazem pelo menos um filho ou não da relação anterior" (Lima, 2008, p. 274). Esse conceito define uma conexão com o ex-parceiro conjugal, assim como com a família deste. Com o divórcio, a conexão formada pela afinidade tende a assumir a feição de crise, contudo, a presença de um filho do primeiro relacionamento conjugal parece ser um dos principais responsáveis pela manutenção dessa conexão ao longo da vida (Dias, 2006).

O recasamento concorre para o aumento da complexidade das relações estabelecidas, uma vez que envolve o entrelaçamento de duas, três, quatro ou mais famílias (Cano et al., 2009). A complexidade relaciona-se ao convívio com os diferentes atores sociais envolvidos. Um exemplo é a interação com o ex-cônjuge e sua família e com os filhos do casamento anterior e os filhos do casamento atual (Biscotti, 2006). Essa realidade apresenta possíveis conflitos que podem ser vivenciados pelo novo casal: os sentimentos de divisão entre o novo par e seus filhos e de divisão entre filhos biológicos e enteados (Lima, 2008). Os conflitos vivenciados dizem respeito, principalmente, aos tipos de obrigações e lealdades estabelecidas no novo arranjo familiar (Marcondes, 2004; Cano et al., 2009). Dias (2006) apresenta exemplos de sentimentos presentes nas delimitações de obrigações e lealdades no recasamento, tais como:

\footnotetext{
A madrasta é vista como alguém que deve amar e cuidar; mas quando o faz, recebe represálias ciumentas da mãe biológica; o filho é visto como alguém que deve sair de casa para as visitas ao pai, deve ser bem tratado e gostar do encontro, mas se gosta demais ou de menos, desperta hostilidade por parte do cônjuge que detém a sua guarda e "fica metido em encrenca"! Do mesmo modo, às vezes a sogra é solicitada a amar a nova mulher $\mathrm{e}$ desgostar da "ex" (do ponto de vista da esposa subsequente); geralmente, a nora espera que a sogra considere a esposa anterior do filho como ex-nora e que esta não desfrute de intimidade em suas vistas à casa dos sogros (p. 154).
}

De acordo com pesquisas, o ajustamento da nova configuração familiar geralmente leva, aproximadamente, de três a cinco anos (Lima, 2008). Esse tempo pode ser maior dependendo das dificuldades encontradas durante o processo. 
Um aspecto que merece destaque e que pode contribuir bastante para as dificuldades no ajustamento do novo casal relaciona-se àquela encontrada entre os ex-cônjuges para delimitar os papéis e as obrigações de cada um. Nesse sentido, a existência de um divórcio litigioso anterior pode prejudicar o ajustamento da nova configuração familiar (Vainer, 1999).

As questões levantadas revelam a necessidade de a família recasada ser considerada a partir de um paradigma de família inteiramente novo, que considere os novos relacionamentos e os papéis além das expectativas geradas com as transformações observadas na sociedade no que diz respeito ao papel do homem e da mulher no casamento.

\section{Teoria das representações sociais}

Optou-se por utilizar a Teoria das Representações Sociais (TRS) neste estudo, uma vez que esta tem se mostrado um instrumento teórico e metodológico interessante para estudos no âmbito da abordagem psicossocial.

As representações sociais são sistemas de interpretação que regem a relação das pessoas com o mundo e com os outros, ou seja, orientam as condutas e as comunicações sociais (Jodelet, 2001). Em outras palavras, esses sistemas de interpretação são estruturados no contexto social através da comunicação entre as pessoas com o objetivo "de moldar a visão e constituir a realidade na qual se vive" (Moscovici, 2001, p. 61). As representações sociais são construções cognitivas e sociais intrinsecamente carregadas de afeto (Banchs, 2011). Dessa forma, verifica-se na estrutura cognitiva "valores, ideias, normas, esquemas que constituem uma impressão histórica, uma memória social" (Banchs, 2011, p. 240).

Um aspecto relevante para a TRS é a participação ativa do indivíduo em sua realidade. O indivíduo interfere, age, modifica e, também, assimila (mas não apenas) a sua realidade. Essa relação entre indivíduo e realidade que se dá por meio dos grupos sociais pode ser considerada intrinsecamente dialética (Philogene, 2011), isso porque sujeito e objeto em sua relação se fundem e se transformam (Trindade, Santos, \& Almeida, 2011). A partir dessa perspectiva, Jodelet (2005) apresenta a importância da experiência para a formação das RS. De acordo com a autora, a experiência possui duas dimensões: vivida e cognitiva. A dimensão vivida "remete a um estado que o sujeito experimenta e sente de maneira emocional; como são exemplos os casos de experiências estéticas, amorosas ou religiosas" (p. 31). A dimensão cognitiva refere-se à construção da realidade por meio da experiência de acordo com as categorias ou formas que são socialmente dadas.

Diante da proposta teórica das TRS, assumiu-se a conjugalidade como um objeto social relevante (Sá, 1993), e que sua configuração sofre influência da experiência do casamento e do recasamento. Serão investigados, então, os elementos que compõem a RS de conjugalidade entre pessoas recasadas.

\section{Método}

Para a realização desta pesquisa foram realizados grupos focais (Morgan, 1997), que têm sido utilizados mais recentemente como método de coleta de dados em pesquisas no campo das representações sociais (Flick, 2004; Veiga \& Gondim, 2001).

A opção por sua utilização ocorreu porque os grupos focais permitem visualizar a construção do conhecimento de forma compartilhada, ou seja, permite ao pesquisador, em um ambiente controlado, o contato com a expressão de representações sociais, entendendo que, no grupo, as pessoas explicitam-nas como uma elaboração de todos, em um processo dinâmico de consenso e dissenso sobre um determinado assunto, no caso, o recasamento.

Optou-se por realizar grupos focais (GF) com homens e mulheres separadamente, seguindo o formato para grupos homogêneos (Morgan, 1997). O único critério de participação no GF foi estar em segundo casamento e ter pelo menos um(a) filho(a) da união anterior. Esse critério foi definido, pois, de acordo com Dias (2006), a presença de um filho de um relacionamento anterior aumenta a tendência de manter uma conexão mais próxima com o ex-parceiro conjugal e a sua família. Dessa forma, foram realizados dois GF com um total de 9 pessoas, sendo 5 mulheres com idades entre 35 e 60 anos; e 4 homens, com idades entre 47 e 61 anos. As pessoas foram selecionadas por meio do critério de bola de neve (Flick, 2004).

A coleta de dados foi dividida em duas partes: na primeira parte foi entregue um questionário que continha questões como idade, estado civil, nível de escolaridade, profissão e renda familiar, para realização da caracterização dos participantes; na segunda parte ocorreu o GF, propriamente dito. O roteiro do GF abrangeu os seguintes núcleos temáticos: (1) cotidiano conjugal; (2) recasamento; (3) filhos.

Antes da realização dos grupos focais foi entregue o Termo de Consentimento Livre e Esclarecido, e sanadas todas as dúvidas sobre o objetivo e os procedimentos da pesquisa quanto a não identificação dos participantes e à liberdade de interromper a participação em qualquer momento, seguindo os procedimentos éticos vigentes.

Para a análise dos dados foi utilizada a análise de discurso. A vertente utilizada foi aquela voltada para a teoria do ato da fala, para a etnometodologia e para a análise da conversação, com ênfase no discurso como forma de ação (Gill, 2002). Para a realização da análise do discurso foi feita a transcrição detalhada do material e, posteriormente, a leitura da transcrição diversas vezes, para a familiarização do material. A codificação dos dados ocorreu em várias etapas. Primeiro, foi feito o recorte do texto dos conteúdos relacionados ao roteiro de entrevista. Segundo, foi feita novamente a leitura desses conteúdos para, então, realizar a terceira etapa, a codificação. A codificação dos dados seguiu a orientação de Spink (1995), que indica a necessidade de mapear os temas emergentes do discurso quando as representações são mais complexas para, então, realizar a análise das dimensões internas da representação dos temas emergentes. Aúltima fase da análise do discurso consiste na interpretação dos significados, ou seja, na análise propriamente dita. A análise do discurso focalizou a compreensão das representações sociais sobre a conjugalidade.

\section{Resultados}

O tempo de duração do primeiro casamento das mulheres variou de 4 anos a 28 anos e dos homens de 7 anos a 16 anos. As mulheres estão em seu segundo casamento em média há 9 
anos e os homens há 13 anos. Das entrevistadas, apenas uma diz estar em união estável e morar em casas separadas. Esta união estável foi contabilizada como casamento, uma vez que a participante assim a considera e disse que eles se vêem todos os dias e possuem uma vida conjugal. Todos os participantes tiveram um ou dois filhos no primeiro casamento e dois homens e duas mulheres possuem filhos no segundo casamento. É importante ressaltar que os filhos do primeiro casamento da maioria dos participantes ficaram com suas respectivas mães após a separação. Apenas um homem permaneceu com os filhos do primeiro casamento. Além disso, todos os participantes residem em bairros considerados de classe média e média alta em uma região metropolitana da região sudeste do Brasil.

A partir da análise das discussões dos GF, os temas emergentes (Spink, 1995) nos discursos foram: casamento e felicidade, a forma de lidar com o outro no cotidiano, filhos e família/parentela. É relevante dizer que nos dois GF realizados houve consenso nas discussões propostas. Apresentam-se, a seguir, primeiramente os relatos do grupo das mulheres e depois os relatos do grupo dos homens.

\section{Grupo de mulheres recasadas}

Em uma primeira avaliação sobre o segundo casamento, as mulheres afirmaram estar felizes e terem alcançado seu objetivo que seria estar em um casamento em que estivessem satisfeitas. A seguir extratos das falas das participantes. "Muito. Muito melhor. Aí eu escolhi uma pessoa que era o que eu sonhava. Eu fui entender o que era um relacionamento. Sabia o que eu estava buscando. Aí foi. Aí eu me realizei”.

Eu não tinha, assim, a menor intenção de ter uma outra pessoa, eu já estava com o que? Uns cinquenta e um para cinquenta e dois anos, então, na minha cabeça, eu estava assim, como dizem os outros, final de linha mesmo (...). Aí, de repente, conheci essa pessoa (...), eu só tenho a agradecer, assim, ter conhecido ele, ter... e, hoje em dia, assim, ele é tudo na minha vida.

Apesar de algumas participantes identificarem diferenças entre o primeiro e o segundo relacionamento, outras avaliam que a mudança não é tão grande, pois os homens não são muito diferentes entre si; a mudança está na maturidade dos envolvidos, principalmente delas, em aceitar as diferenças entre os cônjuges. A seguir estão exemplos de falas das participantes: "Eu hoje tento com o meu [novo] marido. Mas no final só muda de endereço e CPF".

Eu acabei nesse tempo todo vendo que aquelas coisas que eu não suportei, no primeiro casamento, hoje eu vivo mais tranquila, tudo bem. Têm aquelas mesmas coisinhas que eu não quis suportar, hoje, eu estou suportando. Eu acho que quem mudou foi eu.

A diferença vivida entre o primeiro casamento e o segundo está na forma como a relação foi estabelecida. As participantes relatam que a diferença no segundo casamento está na existência de companheirismo e cumplicidade. A fala a seguir comenta a diferença entre os dois casamentos.

Companhia, na vida acho muito difícil quem vive só, eu tive essa experiência: com filho, cachorro, emprego, namorado, eu tinha um monte de coisa, e eu me sentia muito só. Então, o segundo casamento, acho que uma coisa que eu valorizo muito é isso, companheirismo. Eu acho que é uma fusão, que por mais que saia às 7 horas da manhã e só chegue 10,11 horas da noite, a gente está sempre conectado, é uma coisa muito doida, é muito forte.

A vivência conjugal também tem aspectos não tão positivos, mas que é considerado pelas participantes como parte da vivência cotidiana de todo casal, em primeiro ou segundo casamento. De acordo com as participantes, as dificuldades estão nas diferenças de gosto e de hábito entre os cônjuges e na necessidade de ceder alguns espaços da vida social em função da vida conjugal. As falas a seguir apresentam essas dificuldades.

Suportar as manias né? Todos nós temos as nossas, cada um diferente do outro. Eu acho que um pouco a perda da liberdade (...). Eu acho que é isso, um pouco tolhe a nossa liberdade, mas, insignificante, eu diria [diante do ganho que se tem].

Embora as participantes afirmem a existência de uma convivência feliz no segundo casamento, verifica-se que foram necessários ajustes devido à complexidade das relações envolvidas. A segunda união geralmente envolve outros atores sociais além do casal, como filhos do primeiro casamento, exmarido, filhos do novo cônjuge, ex-mulher desse cônjuge, novos sogros, entre outros.

Os filhos foram um fator de grande interferência na decisão pelo segundo casamento. As participantes ou procuraram o aval dos filhos para assumir um compromisso mais duradouro com os parceiros ou ainda esperaram o momento em que os filhos já estavam criados e tinham vida própria. A seguir estão exemplos das falas das participantes. "[O meu namorado] não entrou na minha casa enquanto [meu filho] não convidou. Quando [meu filho] falou: vamos subir, aí ele subiu".

A gente mora em casas separadas. A gente convive assim todos
os momentos, mas a gente mora em casa separada. Eu tenho
uma filha de vinte e oito anos [que mora comigo] e que vai
casar agora no final do ano. Então eu acho que, depois desse
casamento dela, eu vou ter que me decidir o que eu vou fazer,
né? Se a gente vai morar junto ou se vai continuar assim.

Ao estabelecerem um segundo relacionamento algumas participantes tiveram que lidar com a interferência do primeiro marido, que tentava provocar o rompimento do novo relacionamento alegando querer retomar o casamento. Essas interferências se davam através dos filhos ou diretamente com a ex-esposa. A seguir um exemplo dessa interferência na fala de uma participante.

Comecei a namorar, o pai deles ligou para falar e começou a falar na orelha do [meu filho], aí eu logo rasguei o verbo mesmo. Falei: Olha, se ele estivesse interessado, não tinha feito um monte de coisa que fez, essa história está acabada.

Os filhos do novo cônjuge, em alguns casos, podem interferir na relação do novo casal. Nesse caso, observa-se que o pontochave do problema é a criança ter sido ou ainda ser educada de forma diferente daquela que a mulher acredita correta. A seguir está uma fala que exemplifica essa questão. 
Para mim eu posso dizer que o que atrapalhou o nosso casamento foi os filhos. Cada um veio com um filho de antes... Quer dizer os filhos se deram muito bem. E nós começamos a brigar por causa dos filhos. Porque, óbvio, os hábitos do filho dele não eram iguais aos meus com meu filho, e na hora que põe todo mundo junto... eu fiz imediatamente... Não! Não faz isso assim, assim, assim. Pronto, toquei na... E até a gente entrar num acordo nessa área demorou um tempo. Demorou muito. Quase que a gente se separou por causa de tudo isso.

É interessante observar que, apesar das discussões entre os membros do casal, as crianças conseguiram estabelecer uma convivência agradável entre si, parecendo assimilar bem a nova situação (nova casa, novos hábitos, entre outros).

Conhecer a família de origem do novo cônjuge foi um processo de certa forma preocupante para essas mulheres. Havia o receio do que a família pensaria a respeito de uma mulher divorciada e com filhos. Abaixo estão alguns exemplos das falas das participantes.

Eu ser aceita pela família dele foi a maior surpresa para minha vida. Eu sou mais velha que ele, eu tinha um filho de 18 anos a tiracolo, e abriu a porta da casa da tia mais velha e eu entrei, aí, oh, me aceitaram não sei por quê.

"Eu, assim, fui muito bem recebida! Com dois filhos. Quer dizer, ele era solteiro, a minha sogra (...), ela acabou de criar [os meus filhos] (...), até hoje [é] assim".

$\mathrm{O}$ receio de algumas se tornou realidade. Em alguns casos, houve preconceito da família do novo cônjuge em relação à nova esposa. O exemplo a seguir mostra isso.

Porque eu não sou casada com ele, eu sou juntada com ele. Então, quem foi casada com ele foi a primeira esposa dele, que, por sinal, é uma pessoa maravilhosa... mas eles (pais do atual parceiro) fazem questão, eles não me respeitam, não respeitam a minha filha.

O conjunto dos dados revela que os fatores que favorecem a manutenção do casamento desde o seu início, inclusive em relação aos ajustes realizados com os familiares do cônjuge, foram: respeito, companheirismo, cumplicidade e amor. Também é mencionado o humor como um fator que contribui para a duração do casamento.

Observa-se de forma bastante recorrente no relato desse grupo dois fatores preponderantes para a boa avaliação que fazem do segundo casamento: a) a presença de uma parceria, em que as decisões são tomadas em conjunto e as relações de poder são simétricas, e b) se isso não ocorre, os homens são considerados "todos muito parecidos", mas a mulher tem mais maturidade para se adaptar à frustração das expectativas.

Diante dos dados apresentados, observa-se a presença de diferentes objetos sociais na configuração das RS de conjugalidade para as mulheres recasadas. Um dos objetos sociais é o casamento que para essas mulheres articula os elementos amor, cumplicidade e maturidade afetiva. $\mathrm{O}$ novo casamento é representado como o espaço em que se encontra a felicidade, mas também o espaço em que é necessário ceder ao parceiro e conviver com as limitações da individualidade.
Outro objeto observado são filhos. Para essas mulheres os filhos precisam ser cuidados e protegidos, por isso a presença de um novo fator (um homem e seus filhos) que possa interferir na relação mãe e filho é algo que precisa ser muito bem pensado. $\mathrm{O}$ terceiro objeto é a família/parentela. Três elementos constituem esse objeto: o filho do parceiro, a família do parceiro e o exmarido. Esses três elementos de uma forma ou de outra podem interferir na conjugalidade.

\section{Grupo de homens recasados}

O casamento é visto por esse grupo como positivo, o que justifica a opção deles pelo segundo casamento. Afirmam, inclusive, que é a mulher que direciona a vida do marido; nesse sentido, é a mulher que faz com que o homem procure progredir na vida. A seguir alguns exemplos de falas dos participantes. "Você se encontrar como pessoa, a companheira te ajuda muito nesse ponto, quando a gente está solteiro, a gente fica meio desbaratinado".

Eu morava em um apart-hotel e cada dia tinha uma mulher diferente, (...), a minha vida era levar todas as gatinhas que eu podia (...), e aí você entra no ciclo de vida que acaba te desgastando, acaba te atrapalhando a tua vida profissional, suas perspectivas de futuro também ficou meio embaçada, e com a mulher não, você já fica focado no criar, de ter, de produzir, de construir, de ganhar mais dinheiro, e ela te cobra isso (riso), (...) e vai te botando no trilho.

O casamento, para esses homens, é um espaço para a busca da felicidade e, ao mesmo tempo, um espaço de constante negociação com a esposa. O processo de negociação, todavia, é observado como necessário, mas também como um fator que pode ser uma desvantagem do casamento. A ambiguidade aparece quando afirmam desejar uma esposa companheira, que cobre determinados comportamentos do marido, e, ao mesmo tempo, relatam que a negociação com a esposa pode ser desgastante. A seguir está um exemplo de fala que relata essa situação.

"É a questão da negociação, acho que essa é uma coisa que muitas vezes os homens não gostam, e hoje, na relação, acho que você tem que estar permanentemente fazendo essa troca, não tem jeito".

Além da negociação constante, o casamento, para ser duradouro, requer investimento e dedicação. É mencionado que é importante que o homem seja fiel, tenha sabedoria e envolva a espiritualidade na relação. Segue um extrato da fala do participante sobre isso.

\footnotetext{
A mulher contribui muito para a felicidade do casamento, mas nós também podemos contribuir muito, mas para isso tem que estar sensato, voltado para dentro dessa relação, eu quero viver com essa mulher, porque tem hora que dá vontade de largar tudo e ir embora! (...). Mas na verdade não é isso, é aquele momento, então você tem que ter frieza, para poder manter um casamento, sabedoria. Eu acho que envolver Deus num projeto de relacionamento é muito bom.
}

Diante da complexidade das relações entre todos os envolvidos em um segundo casamento, os participantes dizem 
que devem ser feitos os ajustes necessários para que a relação permaneça duradoura, o que nem sempre é fácil. A seguir, uma fala de participante que relata essa realidade.

Eu procuro administrar, tento trazer para dentro da minha casa [os filhos do primeiro casamento], entendeu? Também não tento isso aí para lá também [levar os filhos do segundo casamento para a casa da ex-esposa], mas tento buscar a união, encaixar as pedras aí... mas... é complicado.

Os ajustes envolvem a nova mulher com os filhos e dependem de vários fatores, dois dos quais foram citados: a idade dos filhos e a forma como se deu a separação dos pais. Os filhos (crianças e adolescentes) parecem lidar sem muito problema com a nova esposa do pai. Os filhos, contudo, sofrem grande interferência da mãe, o que pode dificultar ou facilitar o relacionamento com a nova esposa do pai e a nova configuração familiar. A fala a seguir mostra como essa interferência pode ocorrer.

O meu deu um problema sério, sabe o que foi? Como eu separei e juntei logo, a antiga achava que eu tinha alguma coisa com a nova. (...) Ela entende dessa forma, aí o resultado? Proibiu o meu filho nove meses de ir na minha casa.

Outro ajuste necessário envolve os filhos do primeiro casamento com os filhos do segundo casamento. Esses ajustes, como foi observado na fala das mulheres recasadas, parecem ser tranquilos, as crianças conseguem lidar bem com os novos irmãos. Essa realidade também foi observada pelos homens, como indica o extrato a seguir: "[A relação entre irmãos] É muito boa. Apesar de que a diferença de idade é muito grande, mas é muito boa".

A felicidade no casamento para este grupo ocorre na medida em que existe diálogo, afinidade de objetivos, companheirismo e amor. A mulher é vista como uma parceira que vai dar direção à vida do marido. Nesse caso, o papel da mulher é ativo, ela vai cobrar, exigir, persuadir, mas também tem o papel de ser o 'porto seguro' do marido, uma vez que vai ouvir, aconselhar. $\mathrm{O}$ relacionamento com essa mulher exige do marido capacidade de negociação, aspecto nem sempre é avaliado como algo fácil.

O conjunto dos dados do GF dos homens recasados, assim como do GF das mulheres recasadas, mostra que a RS da conjugalidade é constituída pelos seguintes objetos sociais: casamento, filhos e família/parentela. O casamento, para os homens, também é o lugar da felicidade que é conquistada por meio do companheirismo, do amor e da afinidade de objetivos, mas, ao mesmo tempo, é o lugar da negociação com a esposa, o porto seguro e a maneira que o homem encontra para progredir na vida devido à postura da mulher. $\mathrm{O}$ segundo objeto social são os filhos. Os elementos que organizam o sentido desse objeto é a distinção entre os filhos que vivem com o pai na mesma casa e os que não convivem. O terceiro objeto social é a família/parentela. Neste caso, não se observa que a parentela seja a família da nova mulher, mas a ex-mulher, uma vez que é ela que vai interferir na dinâmica conjugal do novo casal.
A presente pesquisa teve como objetivo investigar as representações sociais da conjugalidade em casais recasados. De acordo com os dados, para dar sentido à representação social da conjugalidade no recasamento são articulados vários elementos, além de outros objetos sociais, reafirmando a complexidade do tema já indicada por diversos autores (Bawin-Legros, 2004; Bucher \& Rodrigues, 1990; Cano et al, 2009; Dias, 2006; Souza \& Ramires, 2006) sobre o recasamento.

As representações sociais observadas são constituídas tanto pelo processo de difusão e comunicação quanto pelas experiências pelas quais os participantes passaram. As experiências contribuem para a configuração das RS à medida que se torna uma experiência social, ou seja, quando é reconhecida, compartilhada e confirmada pelos outros. Dessa forma, a experiência social é marcada pelos aspectos sociais de sua enunciação e de sua comunicação, possibilitando, assim, o encontro com as representações sociais (Jodelet, 2005).

As experiências vividas pelos participantes homens e mulheres apresentam certa similaridade, indicando a dificuldade da vivência dessa realidade para ambos os sexos. O casamento é representado como o lugar onde se encontra a felicidade, o que mostra que a vivência da conjugalidade é importante para os indivíduos. Foi à procura desta felicidade que os participantes da pesquisa optaram por casar-se novamente.

De acordo com os dados, para a mulher, a felicidade no casamento ocorre à medida que o homem pode ser um companheiro e um cúmplice; para o homem, quando a mulher é o porto seguro e assume um comportamento ativo no casamento. Embora utilizem palavras diferentes, o conteúdo do discurso que se refere à felicidade no casamento é bastante similar e os dois grupos reconhecem que a felicidade não é tão simples de ser alcançada, uma vez que vários fatores podem interferir.

Um primeiro fator citado por ambos os grupos é a dificuldade de lidar com o outro (cônjuge) no cotidiano conjugal. As mulheres minimizaram esta questão, enquanto os homens evidenciaram a dificuldade de negociar e ceder no cotidiano conjugal. Essa realidade observada apresenta os reflexos das transformações nas relações de gênero (Peixoto, 2007) na conjugalidade. A negociação é um fator que indica certa igualdade entre homens e mulheres no cotidiano conjugal. Não é possível dimensionar, a partir dos dados, como se traduz essa igualdade nas relações conjugais, uma vez que é sabido que o avanço da mulher no espaço público não foi o mesmo que no espaço privado (Garcia \& Tassara, 2001).

Os outros fatores citados referem-se aos filhos, ao ex-cônjuge e à família do novo cônjuge. Observa-se que filhos e parentela organizam-se cada um enquanto objeto de representação social por também incluir elementos cognitivos específicos (Banchs, 2011). Verifica-se que a organização da RS desses objetos é diferente para os homens e para as mulheres. Um dos fatores que interferem nessa configuração é a socialização de gênero (Rocha-Coutinho, 1994), pois observa-se a presença dos papéis tradicionais de gênero nessa configuração. Para a mulher, o filho assume o papel principal em sua vida, dessa forma, coloca-se em segundo plano em relação a este, aspecto que não é mencionado pelos homens. A parentela, para as mulheres, é a família do novo marido e a relação estabelecida com essa família é permeada 
pelo medo de uma mulher com filho não ser considerada uma boa escolha. Para os homens, a parentela, basicamente, é a exesposa que interfere e pode prejudicar tanto a relação com o filho quanto com a nova parceira. Nestes casos, a única forma de lidar com isso é tentar equilibrar a influência da mãe sobre o filho, contudo, não é uma questão tão simples, devido à relação estabelecida entre mãe e filho.

Pode-se afirmar que a organização da RS da conjugalidade no recasamento sofre influência das dificuldades cotidianas na redefinição do conteúdo dos papéis, funções, responsabilidades e poder (Carter \& McGoldrick, 2001; Souza \& Ramirez, 2006) da maioria dos atores sociais envolvidos. Dessa forma, o recasamento possui uma complexidade maior se comparado com o primeiro casamento, como apresentam alguns dos autores citados anteriormente (Biscotti, 2006 Carter \& McGoldrick, 2001; Dias, 2006), por envolver diversos atores sociais.

Uma das grandes dificuldades no ajustamento da nova composição familiar é compartilhar determinados papéis, como o de pai e de mãe. Na nova composição familiar, por exemplo, a mãe vai precisar compartilhar a maternidade com outra mulher que vai assumir os filhos dela quando as crianças forem visitar o pai. Isso exige, por parte dos envolvidos, um redimensionamento e uma negociação dos papéis que irão desempenhar. As pessoas, normalmente, não estão preparadas para lidar com essa realidade (Kunrath, 2006), até porque é uma situação nova da qual ainda não existem modelos a serem observados. É interessante notar, entretanto, que essas dificuldades não parecem ser vivenciadas pelas crianças, fato que contradiz a literatura sobre o assunto. Diante deste achado, sugere-se que pesquisas sejam realizadas para a sua melhor compreensão.

Um fato significativo e que merece novas investigações é o discurso de um pai que menciona um comportamento feminino que, em princípio, não leva em consideração o bem-estar do filho: a proibição da visita do filho como forma de ferir o pai. Este comportamento faz com que o filho seja privado da presença do pai em sua vida. Em alguns casos, a mãe pode chegar a incutir falsas "verdades" sobre o pai com o objetivo de fazer com que o filho se afaste dele. Este comportamento tem sido estudado desde 1985, por Gardner, que o denominou de Síndrome de Alienação Parental. No Brasil, apenas recentemente, pesquisas têm sido realizadas sobre o assunto (Colcerniani, 2008; Fonseca, 2006; Lago \& Bandeira, 2008). Apesar disso, tem havido grande discussão sobre a temática no meio jurídico e no âmbito da psicologia jurídica, indicando a relevância do assunto. A partir dessas discussões, foi proposto no Congresso Nacional, em 2008, um projeto de lei que foi transformado, em 2010, na Lei $\mathrm{n}^{\mathrm{o}}$ 12.318. A referida lei define instrumentos para punir o genitor que cria condições para o estabelecimento da Síndrome de Alienação Parental. Devido à importância do assunto, é necessário que estudos específicos sejam realizados para o seu aprofundamento.

Outro fato observado diz respeito à forma como o homem separado/divorciado lida com a nova condição de solteiro, que gira em torno de bebida, mulheres e amigos. Esta realidade é representada socialmente como uma vida desregrada, que pode contribuir para a estagnação e o declínio profissional. Uma forma de evitar essa condição é via o recasamento, mesmo que a experiência anterior não tenha sido exitosa (Silva, 2009).
Com os dados obtidos, verificou-se que a RS da conjugalidade é constituída por objetos de representações (Sá, 1993) como família, casamento, amor e, também, gênero. Sendo assim, o campo representacional da conjugalidade que seria constituído por diversos elementos que lhe dão significados (Moscovici, 1961), configura-se como um sistema de representações (Silva, 2009). Um sistema de representações pode ser entendido como um conhecimento socialmente partilhado formado por um conjunto de objetos representacionais, que, por sua vez, são constituídos por um conjunto de elementos representacionais. Todos os objetos e os elementos representacionais presentes em um sistema representacional estão interrelacionados de tal forma a dar coerência e sentido a esse sistema representacional, como uma rede de significações e símbolos. A abrangência do sistema representacional de um objeto pode ser bastante extensa em termos de objetos representacionais. Neste caso, para efeito de viabilidade de realização de pesquisas, cabe ao pesquisador fazer o recorte que interesse à sua pesquisa.

$\mathrm{Na}$ presente pesquisa verifica-se, então, que objeto social conjugalidade por sua abrangência e complexidade não pode ser estudado sem abordar as questões referentes a, por exemplo, gênero, família nuclear, família extendida, amor, entre outros, uma vez que a sua vivência e compreensão incorpora todas essas questões.

\section{Considerações finais}

A partir do conjunto de resultados encontrados, verificouse que a conjugalidade configura-se como um sistema representacional (Silva, 2009). Além disso, também foi possível apreender aspectos sobre o fenômeno do recasamento que corroboram algumas pesquisas sobre o assunto e as complementam. Primeiro, há um desejo por parte das pessoas separadas de buscar um vínculo conjugal satisfatório. Assim, após a separação, há uma tendência de as pessoas casaremse novamente caso encontrem alguém para compartilhar a intimidade. Segundo, as relações estabelecidas possuem um nível de complexidade que faz com que essa segunda relação conjugal tenha uma dinâmica diferente da primeira relação. Terceiro, as crianças conseguem lidar adequadamente com as mudanças vivenciadas quando os pais mantêm um relacionamento adequado após a separação e, depois, com o recasamento. Quarto, no recasamento a relação conjugal tende a ser mais igualitária em termos de papéis de gênero. Quinto, os homens parecem apresentar a necessidade de uma parceria conjugal para a organização da vida emocional, familiar e profissional.

A utilização da abordagem psicossocial demonstrou-se uma alternativa interessante à perspectiva clínica para compreender o fenômeno do recasamento em sua complexidade. $\mathrm{O}$ fato de articular a TRS nesse contexto possibilitou a identificação e a formação do sistema representacional da conjugalidade indicando que é possível, inclusive, ampliar a abordagem para outras dimensões, cobrindo dessa forma em pesquisas futuras objetos sociais (Sá, 1993) que também fazem parte da conjugalidade no recasamento. Além disso, essa perspectiva ainda permitiu identificar as formas como os atores sociais envolvidos lidam e relacionam-se na nova configuração familiar 
com o recasamento.

\section{Referências}

Araújo, M. F. (2002). Amor, casamento e sexualidade: velhas e novas configurações. Psicologia: Ciência e Profissão, 22(2), 70-77.

Banchs, M. A. (2011). Leitura epistemológica da teoria das representações sociais. Reflexões rumo a um sentido comum menos comum e com mais sentido. In A. M. O. Almeida, M. F. S. Santos \& Z. A. Trindade (Orgs.), Teoria das representações sociais: 50 anos (pp. 225-258). Brasília: Technopolitik.

Bawin-Legros, B. (2001). Families in Europe: a private and political stake intimacy and solidarity. Current Sociology, 49(5), 49-65.

Bawin-Legros, B. (2004). Intimacy and the new sentimental order. Current Sociology, 52(2), 241-250.

Biscotti, O. (2006). Terapia de pareja: una mirada sistémica. Buenos Aires: Lumens Humanitas

Bucher, J. S. N. R., \& Rodrigues, M. A. M. (1990). Recasamento e recomposição familiar: questões metodológicas, de linguagem e das teorias. Psicologia: Teoria e Pesquisa, 6(2), 155-169.

Bulcroft, R., Bulcroft, K., Bradley, K., \& Simpson C. (2000).The management and production of risk in romantic relationships: a postmodern paradox. Journal of Family History, 25(1), 63-92.

Cano, D. S., Gabarra, L. M., Moré, C. O., \& Crepaldi, M. A. (2009). As transições familiares do divórcio ao recasamento no contexto brasileiro. Psicologia: Reflexão e Crítica, 22(2), 214-222.

Colcerniani, C. B. (2008). Direito de família: um novo rumo ao lado da psicologia jurídica e da afetividade. Vox Forensis 1, 224-233.

Dessen, M. A., \& Braz, M. P. (2005). As relações maritais e sua influencia nas relações parentais: implicações para o desenvolvimento da criança. In M. A. Dessen \& A. L. Costa Junior (Orgs.), A ciência do desenvolvimento humanos. tendências atuais e perspectivas futuras (pp. 132-151). Porto Alegre: Artmed.

Dias, M. L. (2006). Família \& terapeutas: casamento, divórcio e parentesco. São Paulo: Vetor.

Féres-Carneiro, T., Neto, O. D. (2010). Construção e dissolução da conjugalidade: padrões relacionais. Paidéia, 20(46), 269-278.

Flick, U. (2004). Uma introdução à pesquisa qualitativa. $2^{\underline{\underline{a}}}$ edição. Porto Alegre: Bookman.

Fonseca, P. M. P. C. (2006). Síndrome de alienação parental. Pediatria, 28(3), 162-168.

Garcia, M. L. T., \& Tassara, E. T. O. (2001). Estratégias de enfrentamento do cotidiano conjugal. Psicologia: Reflexão e Crítica, 14(3), 635-642.

Giddens, A. (1993). A transformação da intimidade: sexualidade, amor e erotismo nas sociedades modernas. São Paulo: Editora UNESP.

Gill, R. (2002). Análise de discurso. In M. W. Bauer \& G. Gaskell (Orgs.), Pesquisa qualitativa com texto imagem e som: um manual prático (pp. 244-270). Petrópolis, RJ: Vozes.

Gomes, I. C., \& Paiva, M. L. S. C. (2003). Casamento e família no Século XXI: possibilidades de holding. Psicologia em Estudo, 8(Num. Esp.), 3-9.

Guerreiro, I. C. Z., Oliveira, A. L., \& Souza, M. T. S. (1999). Famílias recasadas: uma análise da literatura psicológica. Psicologia Revista, 8, 77-96.

IBGE. Instituto Brasileiro de Geografia e Estatística (2010). Estatísticas do Registro Civil.

Jodelet, D. (2001). Representações Sociais: um domínio em expansão. In D. Jodelet. (Org.), As representações sociais (pp.17-41). Rio de Janeiro, RJ: EdUERJ.
Jodelet, D. (2005). Experiência e representações sociais. In M. S. S. Menin \& A. M. Shimizu (Orgs.), Experiência e representação social: questões teóricas e metodológicas (pp. 23-56). São Paulo: Casa do Psicólogo.

Kunrath, L. H. (2006). Recasamento: novas oportunidades para o espaço conjugal. Pensando Famílias, 10(1), 101-112.

Lago, V. M., \& Bandeira, D. R. (2008). As práticas em avaliação psicológica envolvendo disputa de guarda no Brasil. Avaliação Psicológica, 7(2), 223-234.

Lei n. 12.318, de 26 de agosto de 2010. (2010, 27 de agosto). Dispõe sobre a alienação parental. Diário Oficial da União, seção 1.

Lima, I. B. (2008). Família reconstruída: a nova construção da conjugalidade. Revista de Enfermagem UFPE On Line, 2(3), 269-278.

Marcondes, G. S. (2004). As famílias de segundas uniões: um elo perdido na demografia da família. In ABEP(Orgs.), XIV Encontro Nacional de Estudos Populacionais. Trabalho completo (pp. 1-16). Caxambu: Autor.

McGoldrick, M. \& Carter, B. (2001). Constituindo uma família recasada. In B. Carter \& M. McGoldrick (Orgs.), As mudanças no ciclo de vida da família: uma estrutura para a terapia familiar (pp. 344-369). Porto Alegre: Artmed.

Morgan, D. L. (1997). Focus groups as qualitative research. $2^{\underline{a}}$ edição. California, EUA: Sage Publications.

Moscovici, S. (1961). La psychanalyse, son image et son public: étude sur la representation sociale de la psychanalyse. Paris: Presses Universitaires de France.

Moscovici, S. (2001). Das representações coletivas às representações sociais: elementos para uma história. In D. Jodelet (Org.). As representações sociais (pp. 45-66). Rio de Janeiro: EdUERJ.

Peixoto, C. E. (2007). As transformações familiares e o olhar do sociólogo (prefácio). In F. Singly (Org.), Sociologia da família contemporânea (pp.1128). Rio de Janeiro: FGV

Philogene, G. (2011). O alcance das representações sociais: impacto e ramificações. In A. M. O. Almeida, M. F. S. Santos \& Z. A. Trindade (Orgs.), Teoria das representações sociais: 50 anos (pp. 371-389). Brasília: Technopolitik.

Rocha-Coutinho, M. L. (1994). Tecendo por trás dos panos: a mulher brasileira nas relações familiares. Rio de Janeiro: Rocco.

Sá, C. (1993). Representações sociais: o conceito e o estado atual da teoria. In M. J. Spink (Org.), O conhecimento no cotidiano: as representações sociais na perspectiva da psicologia social (pp. 19-45). São Paulo: Brasiliense.

Silva, P. O. M. (2009). Vivendo casamentos, separações e recasamentos: um estudo sobre o campo representacional da conjugalidade. (Tese de Doutorado). Universidade Federal do Espírito Santo, Vitória. (doi:10.1177/0011392101495006)

Souza, R. M., \& Ramires, V. R. (2006). Amor, casamento, família, divórcio... e depois: segundo as crianças. São Paulo: Summus.

Spink, M. J. (1995). Desvendando as teorias implícitas: uma metodologia de análise das representações sociais. In P. Guareschi \& S. Jovchelovitch (Orgs.), Textos em representações sociais (pp. 117-145). $8^{\text {a }}$ edição. Petrópolis, RJ: Vozes.

Trindade, Z. A., Santos, M. F. S., \& Almeida, A. M. O. (2011). Ancoragem: notas sobre consensos e dissensos. In A. M. O. Almeida, M. F. S. Santos \& Z. A. Trindade (Orgs.), Teoria das representações sociais: 50 anos (pp. 101-121). Brasília: Technopolitik.

Vainer, R. (1999). Anatomia de um divórcio interminável. São Paulo: Casa do Psicólogo.

Veiga, L., \& Gondim, S.M.G. (2001). A utilização de métodos qualitativos na ciência política e no marketing político. Opinião Pública, 7(1), 1-15. 
Priscilla de Oliveira Martins-Silva, doutora em Psicologia pela Universidade Federal do Espírito Santo, é professora Adjunta da Universidade Federal do Espírito Santo. Endereço para correspondência: Rua Alda Siqueira Mota, 89/ 401 - Praia da Costa, Vila Velha - ES. CEP: 29100-440. Tel.: (27) 3299 3778. Fax: (27) 3349 9339. Email: priscillamartinssilva@gmail.com

Zeidi Araujo Trindade, pós-doutora em Psicologia pela Universidade de São Paulo, doutora em Psicologia pela Universidade de São Paulo, é professora titular da Universidade Federal do Espírito Santo. Email: zeidi.trindade@gmail.com

Annor da Silva Junior, doutor em Administração pela Universidade Federal de Minas Gerais, é professor adjunto da Universidade Federal do Espírito Santo. Email: annorsj@gmail.com e/ou annor.silva@ufes.br 